\title{
lodocyclization in Aqueous Media and Supramolecular Reaction Control Using Water-Soluble Hosts
}

Treyvon Bokoskie, ${ }^{a}$ Chris Cunningham, ${ }^{\mathrm{b}}$ Cory Kornman, ${ }^{\mathrm{b}}$ Tanay Kesharwani, ${ }^{\mathrm{b}}$ and Mahesh Pattabiramana*

${ }^{a}$ Department of Chemistry, University of Nebraska Kearney, Kearney, NE-68849

${ }^{\mathrm{b}}$ Department of Chemistry, University of West Florida, Pensacola, FL-32514

email: tkesharwani@uwf.edu, pattabiramm2@unk.edu

Index

a. Synthesis of guests - procedure

b. NMR data

c. Time-dependent conversion

d. Computed structures and data

e. UV-Vis and fluorescence spectra

\section{A. Synthesis of guests - general procedure}

To a vial containing 2-iodoanisole $(4 \mathrm{mmol})$ in $\mathrm{Et}_{3} \mathrm{~N}(12 \mathrm{~mL})$, desired alkyne $(4.4 \mathrm{mmol})$ was added. The mixture was flushed with nitrogen and $\mathrm{PdCl}_{2}\left(\mathrm{PPh}_{3}\right)_{2}(0.2 \mathrm{mmol})$ and $\mathrm{Cul}(0.4 \mathrm{mmol})$ were added subsequently. The mixture was allowed to stir at room temperature for 24 hours. The reaction mixture was concentrated under vacuum, adsorbed to silica gel, and purified via column chromatography using hexanes and ethyl acetate $(20: 1)$ as the eluent.

\section{B. ${ }^{1} \mathrm{H}$ NMR spectra of guests}

- Compound 1a $\left(\mathrm{CDCl}_{3}\right)$ : $3.92(\mathrm{~s}, 3 \mathrm{H}), 6.90-6.94(\mathrm{~m}, 2 \mathrm{H}), 7.28-7.38(\mathrm{~m}, 4 \mathrm{H}), 7.50$ (dd, $J=7.5 \mathrm{~Hz}, 1.5$ $\mathrm{Hz}, 1 \mathrm{H}), 7.54-7.58(\mathrm{~m}, 2 \mathrm{H}$. All other spectral properties were identical to those previously reported. ${ }^{1}$

- Compound 1b $\left(\mathrm{CDCl}_{3}\right): 3.82 \mathrm{ppm}(\mathrm{s}, 3 \mathrm{H}), 3.88 \mathrm{ppm}(\mathrm{s}, 3 \mathrm{H}), 6.83-6.93(\mathrm{~m}, 4 \mathrm{H}), 7.26(\mathrm{t}, \mathrm{J}=8.0 \mathrm{~Hz}$, $1 \mathrm{H}, 7.46-7.50(\mathrm{~m}, 4 \mathrm{H})$. All other spectral properties were identical to those previously reported. ${ }^{1}$

- Compound 1c $\left(\mathrm{CDCl}_{3}\right)$ : $3.91(\mathrm{~s}, 3 \mathrm{H}), 6.91-6.97(\mathrm{~m}, 2 \mathrm{H}), 7.34$ (dd, J = 8.4 Hz, 1.6 Hz, 1H), 7.49 (dd, J $=7.6 \mathrm{~Hz}, 1.6 \mathrm{~Hz}, 1 \mathrm{H}), 7.50-7.61(\mathrm{~m}, 4 \mathrm{H})$. All other spectral properties were identical to those previously reported. ${ }^{2}$ 


\section{Compound 1a}

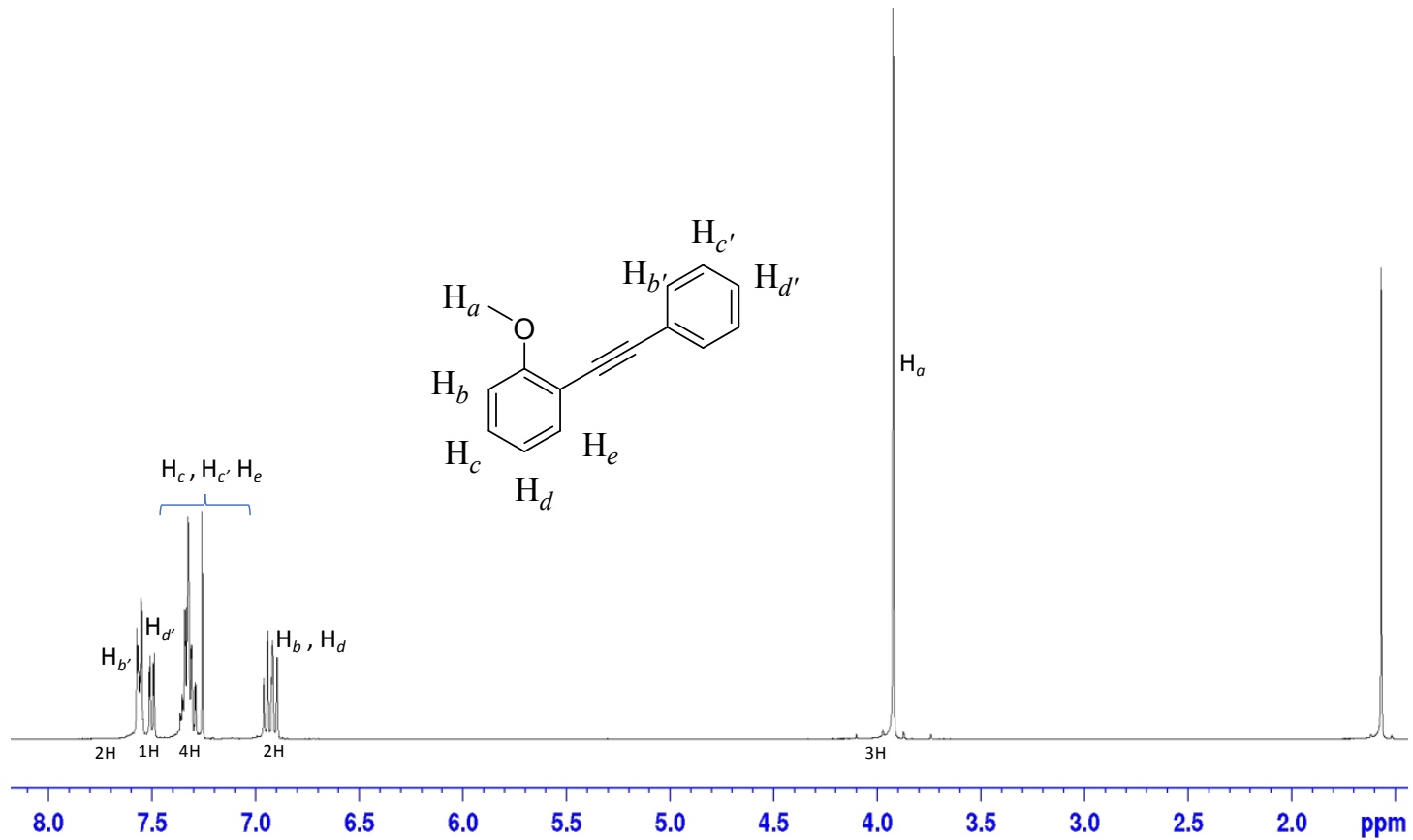

Figure S1. Proton NMR of compound $1 \mathrm{a}$ in $\mathrm{CDCl}_{3}$

Mass spectral data for $1 \mathrm{a}$ (expected molecular mass: $208.09 \mathrm{~g} / \mathrm{mol}$ )

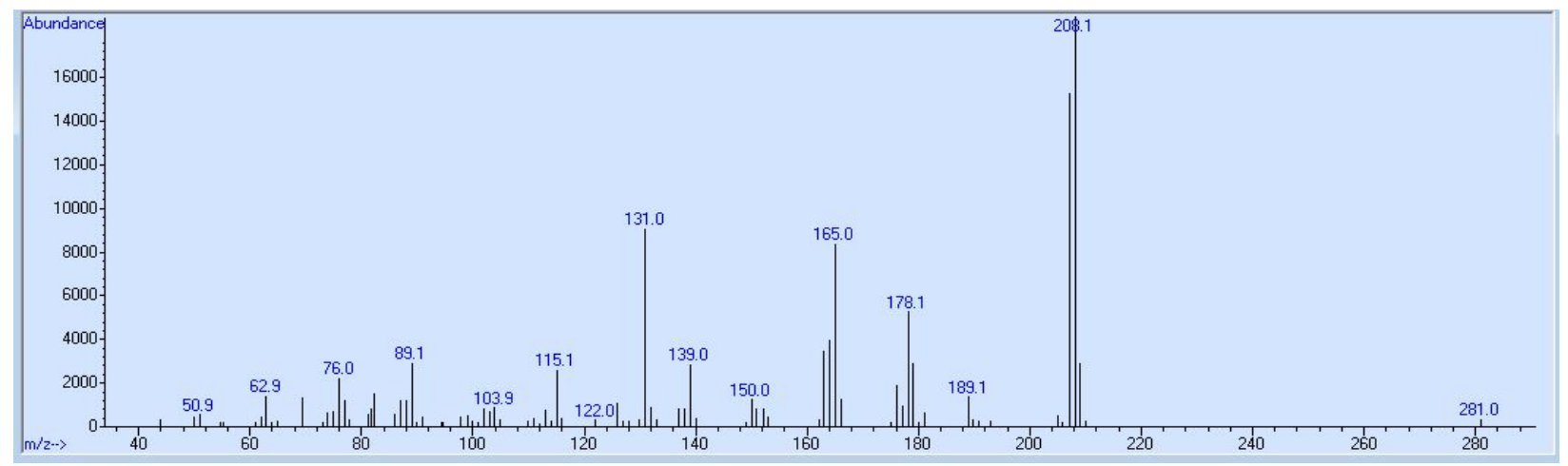

Mass spectral data for $\mathbf{2 a}$ (expected molecular mass: $320.13 \mathrm{~g} / \mathrm{mol}$ )

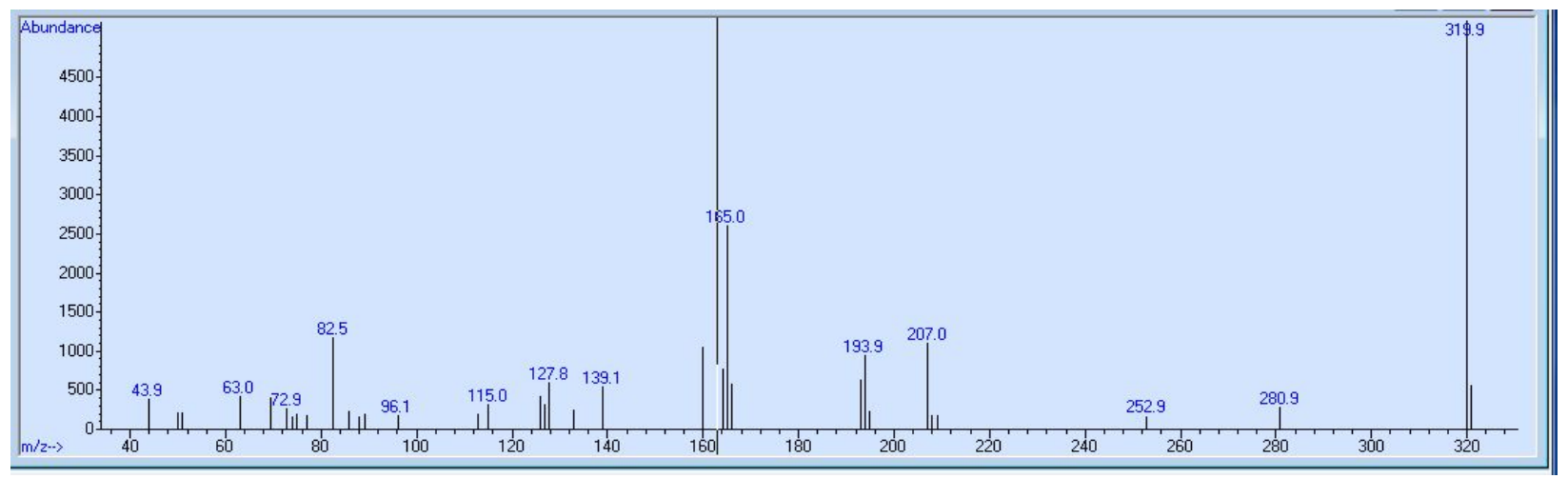




\section{Compound 1b}

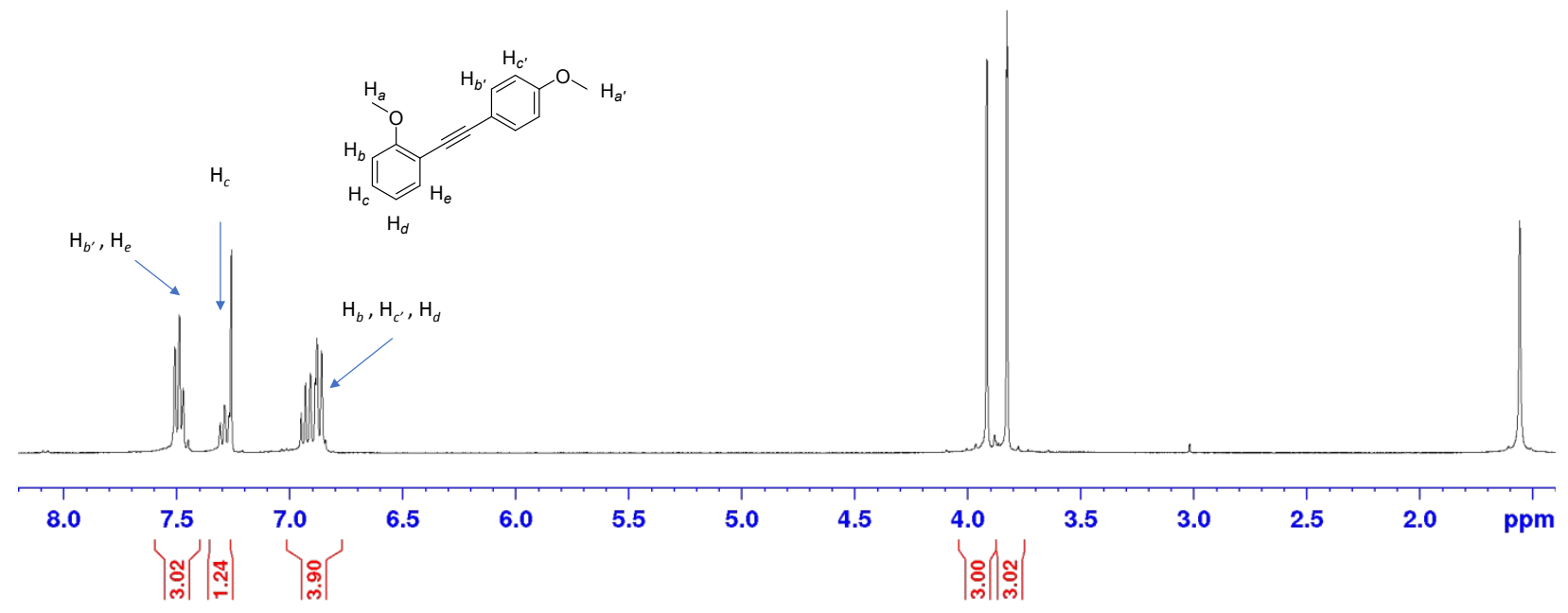

Figure S2. Proton NMR of compound $1 \mathrm{~b}$ in $\mathrm{CDCl}_{3}$

\section{Compound 1c}

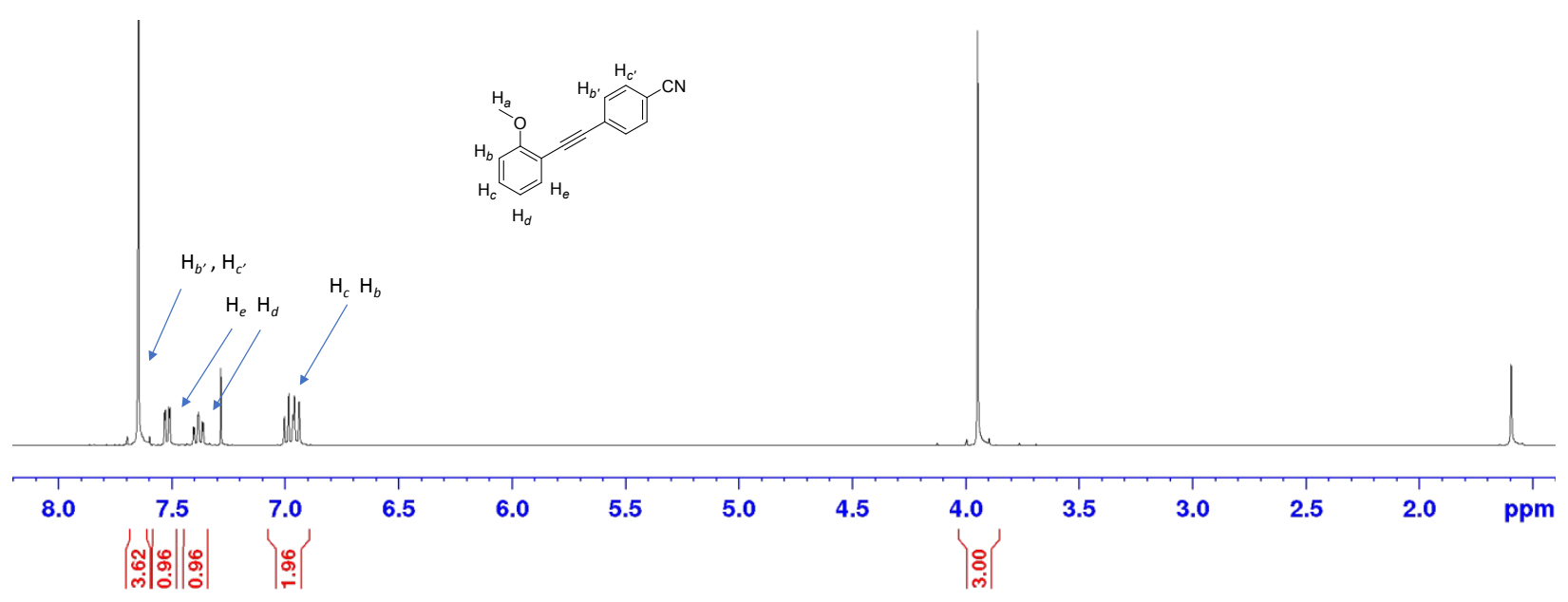

Figure S3. Proton NMR of compound 1c in $\mathrm{CDCl}_{3}$.

Note: The unusual pattern of the phenylene protons are confirmed based on work published by Rubin et al., J Am Chem Soc. 2005, 127(29), 10243-9. 


\section{Time-dependent conversion experiment}

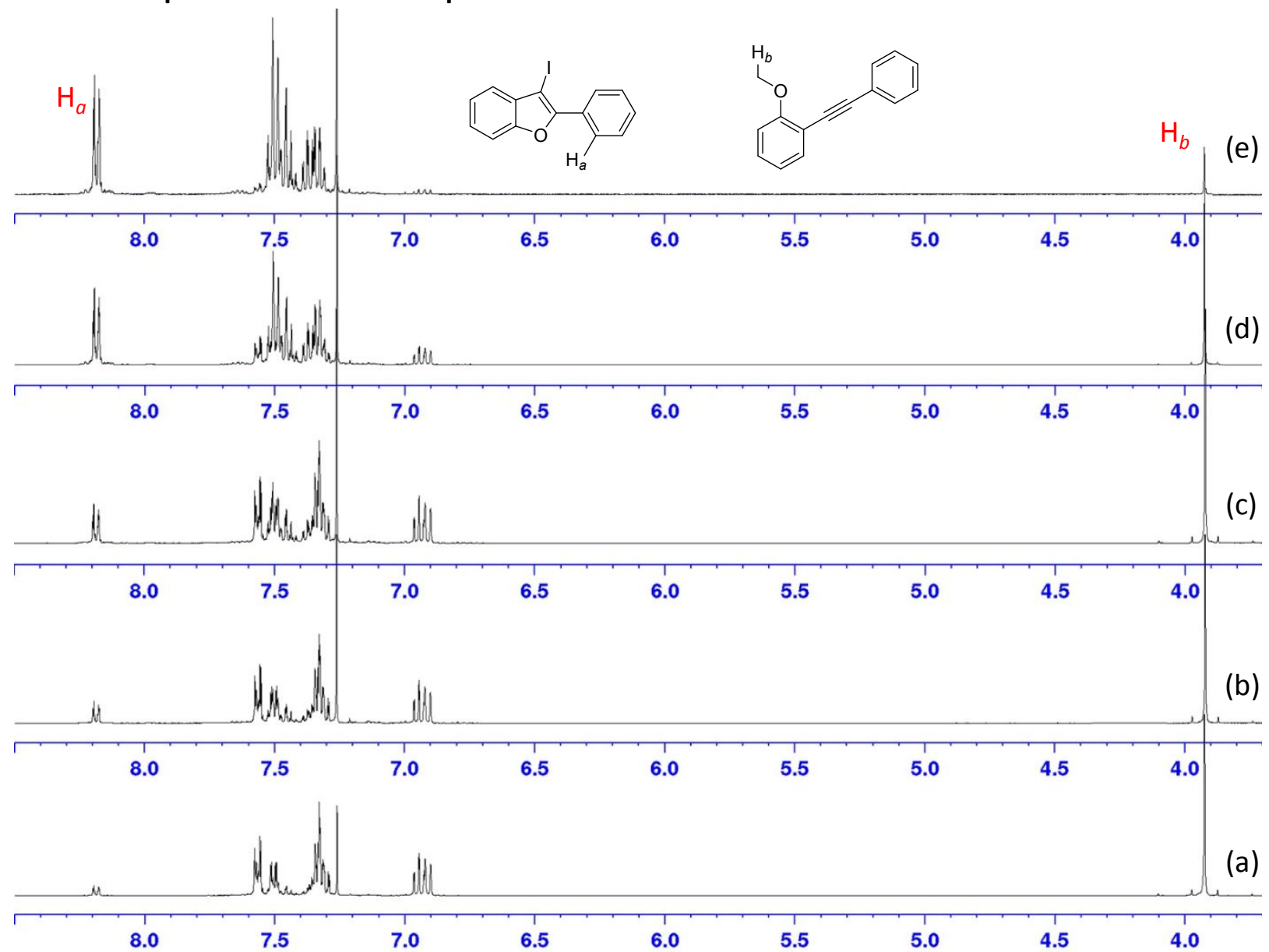

Figure S4. Time-dependent reaction progress for 1:5:5 (reactant:Nal:CuSO${ }_{4}$ ) in aqueous slurry. Reaction mixture was extracted after 2, 6, 10, 20 and $24 \mathrm{hrs}$ (a $\rightarrow$ e respectively), dried and spectra recorded in $\mathrm{CDCl}_{3}$.

Percent of product $=\left(\frac{\left[\frac{\mathrm{H}_{a}}{2}\right]}{\left[\frac{\mathrm{H}_{a}}{2}\right]+\left[\frac{\mathrm{H}_{b}}{3}\right]}\right) \times 100$ 


\section{Computational chemistry structures and parameters}

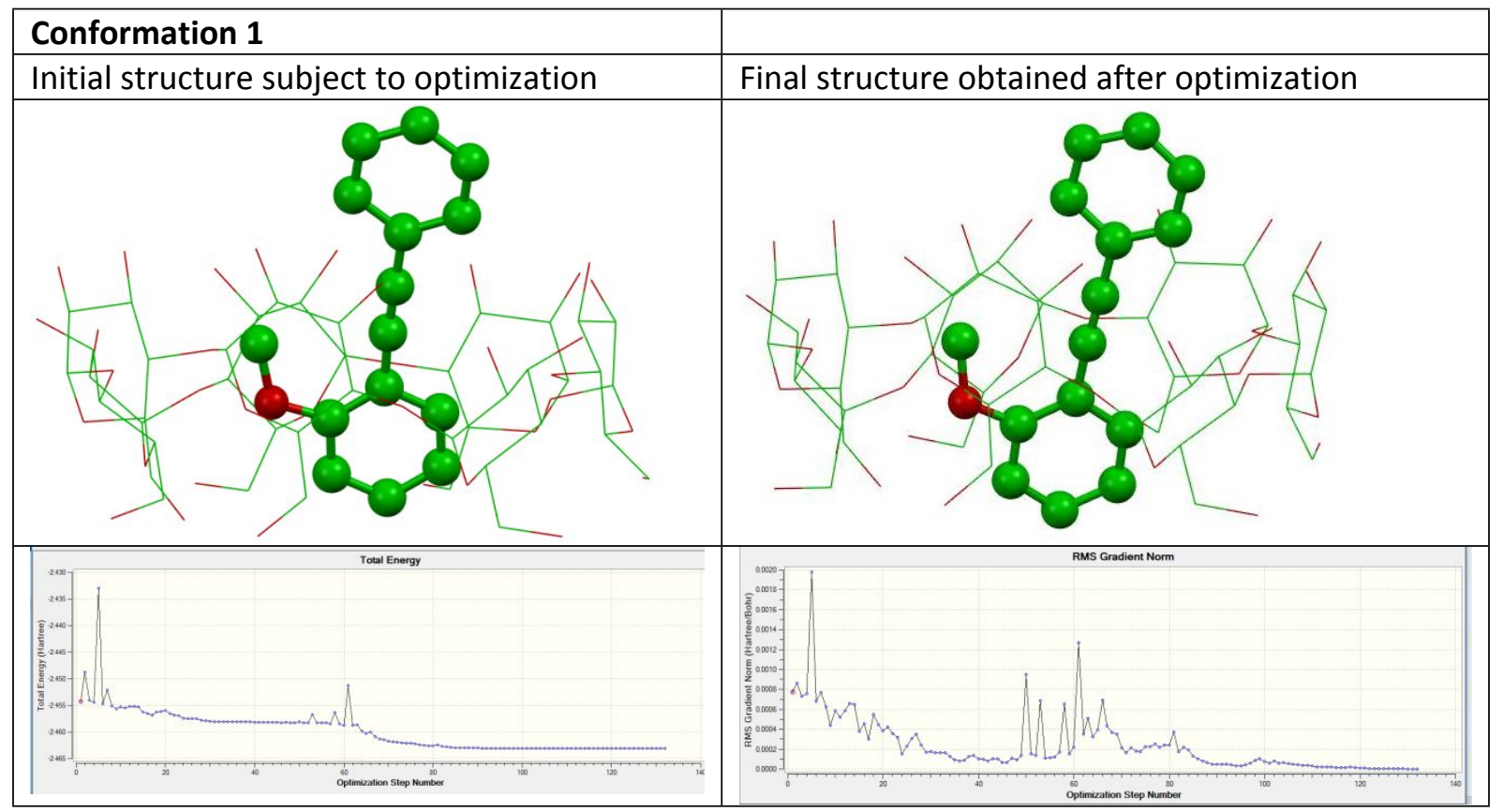

Figure S5. Complex structures involving conformation 1 optimized using Gaussian '09 SE PM6 (top). Bottom panel shows number of intermediary optimized structures, and RMS in energy.

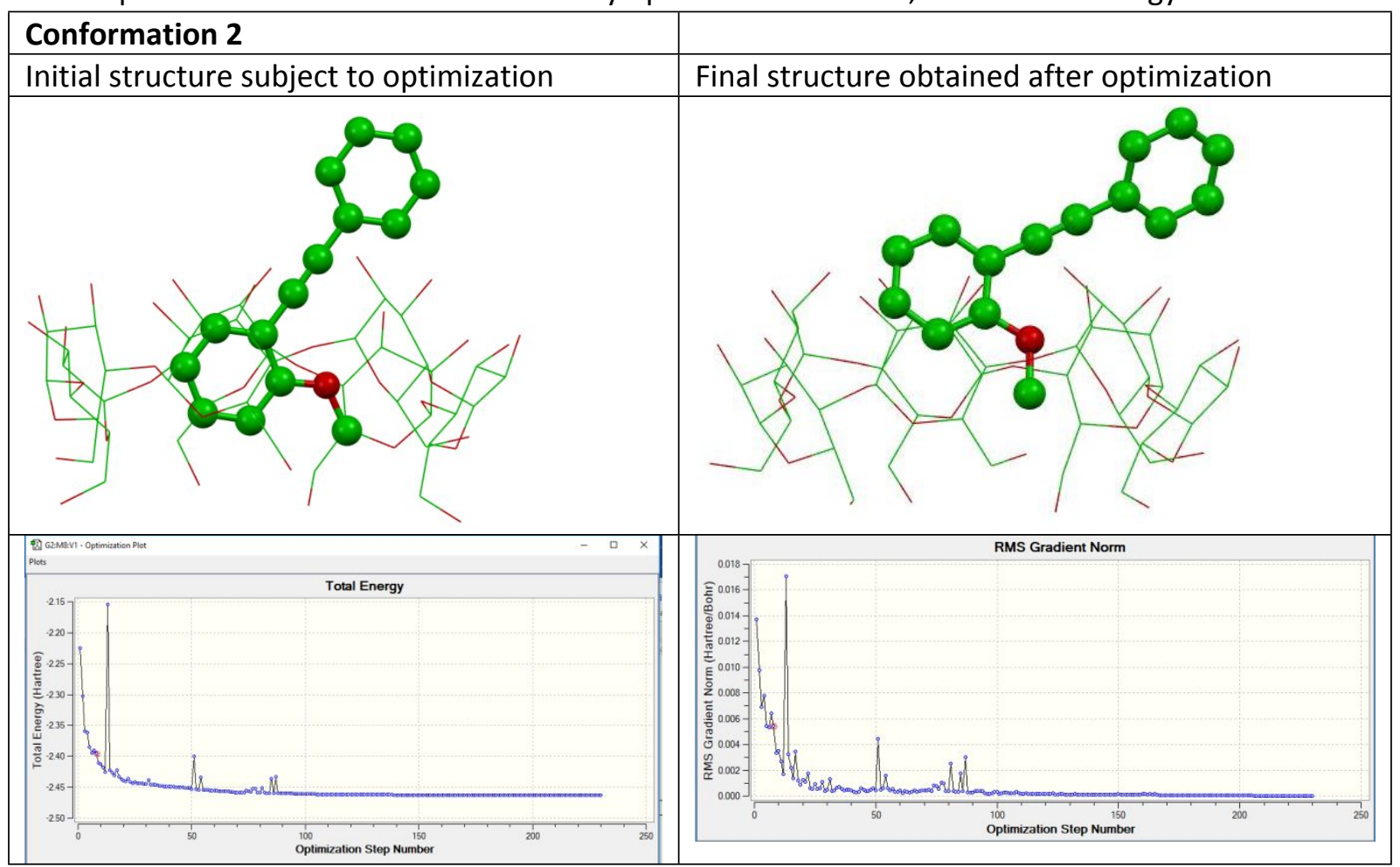

Figure S6. Complex structures involving conformation 2 optimized using Gaussian '09 SE PM6 (top). Bottom panel shows number of intermediary optimized structures, and RMS in energy. 


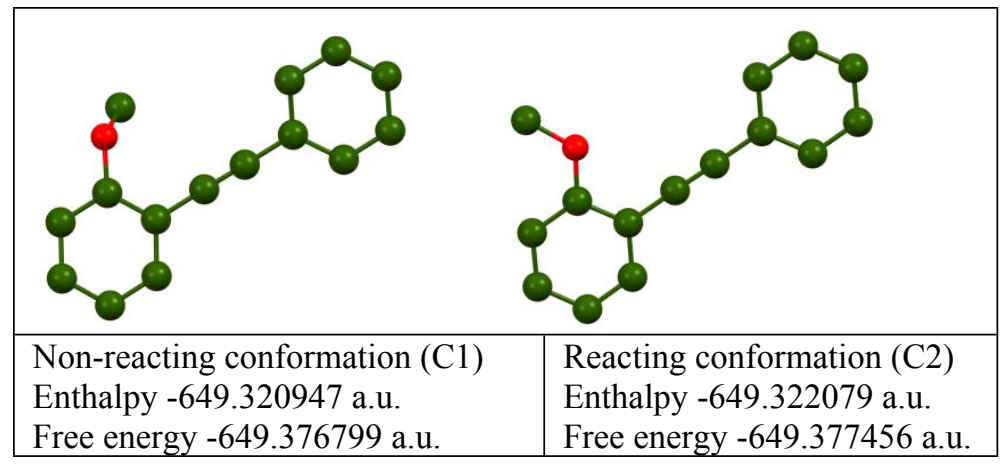

Figure S7. Conformations of free guests in the gas phase

E. UV-Vis and fluorescence titration spectra

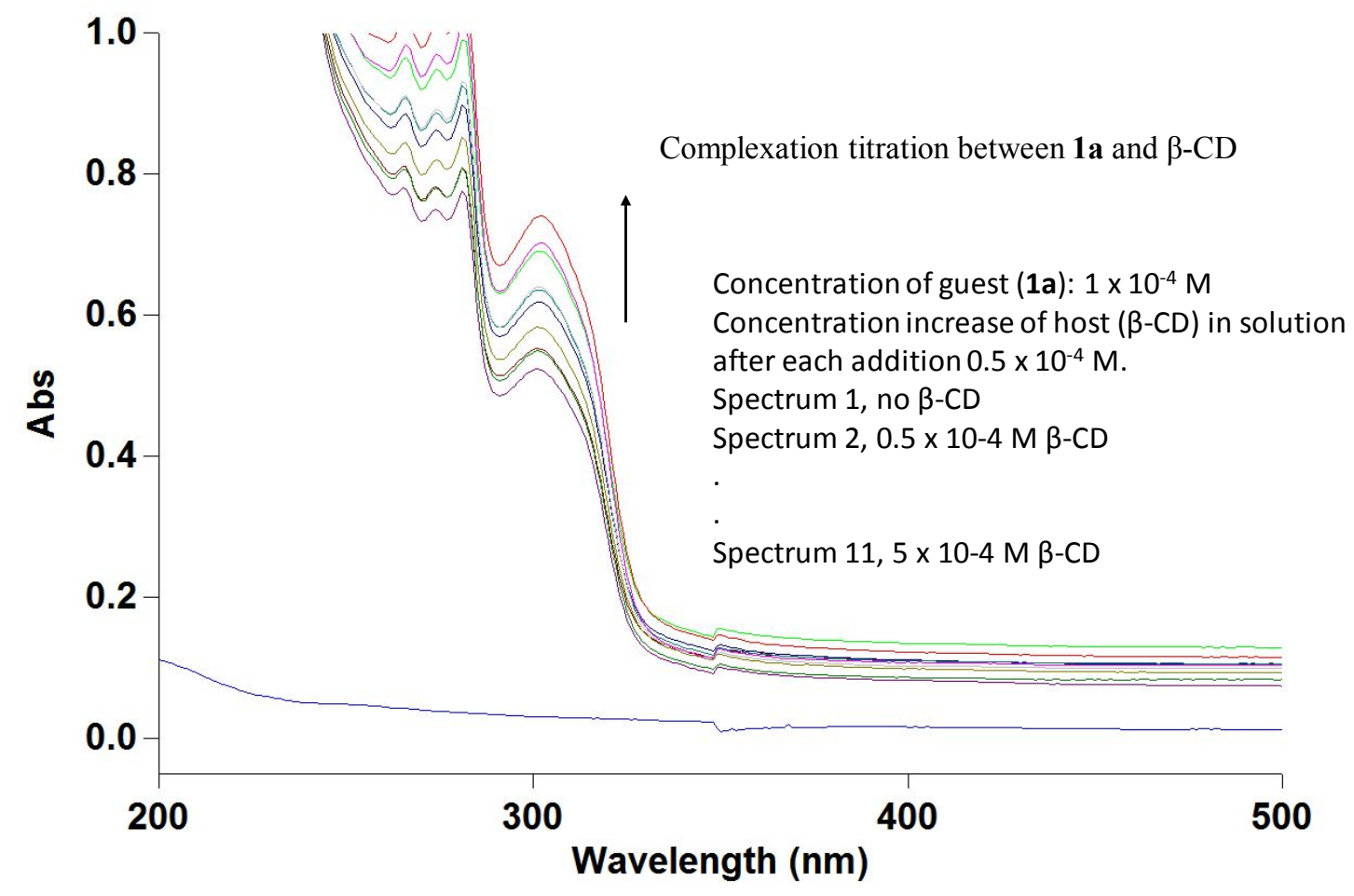

Figure S8. UV-Vis Titration between 1a and $\beta-C D$. The baseline of spectra with each addition of $\beta-C D$ to the guest increases as the complex formation results in cloudiness (precipitation). 


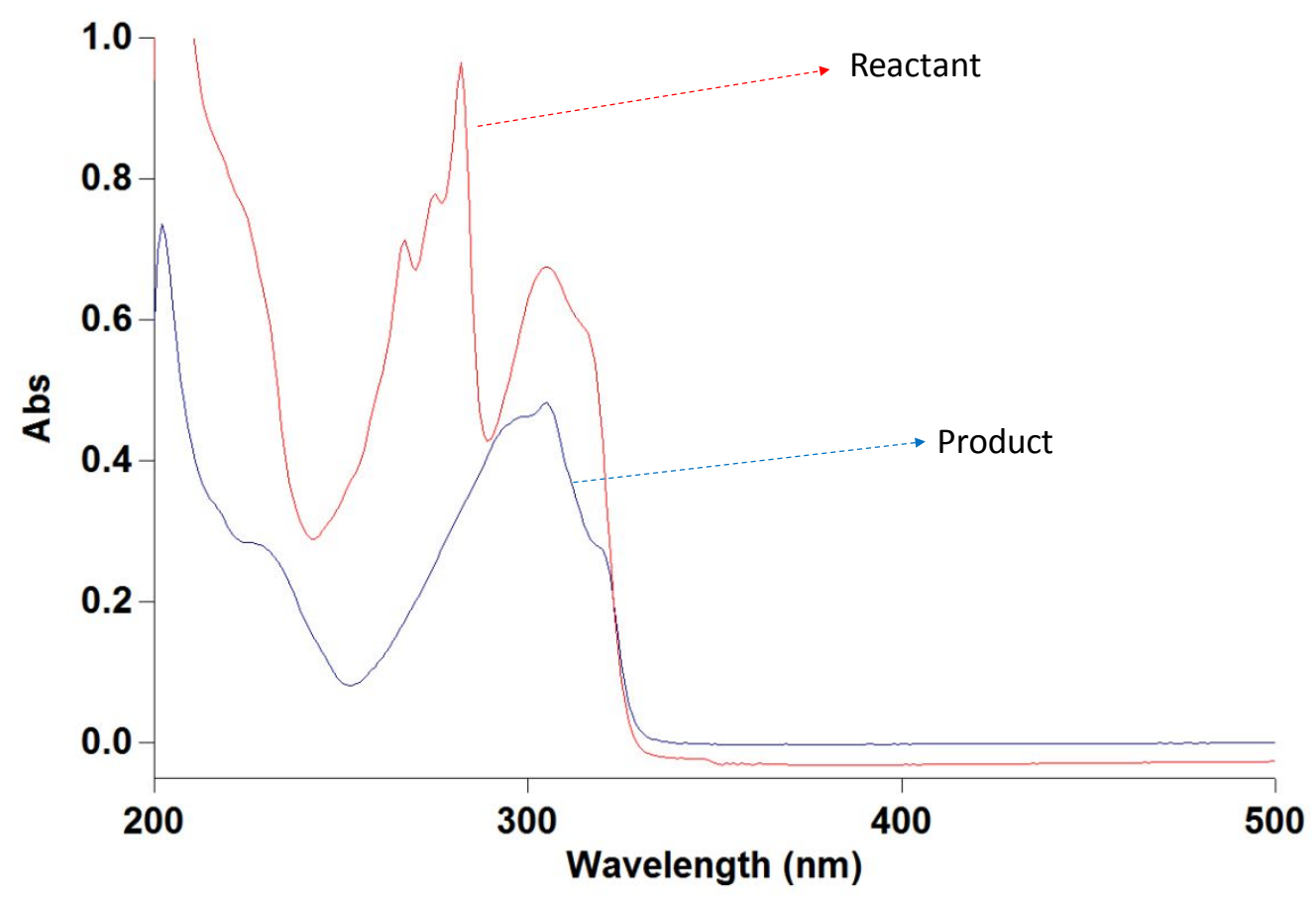

Figure S9. UV-Vis spectrum of pure reactant and product $\left(10^{-4} \mathrm{M}\right)$

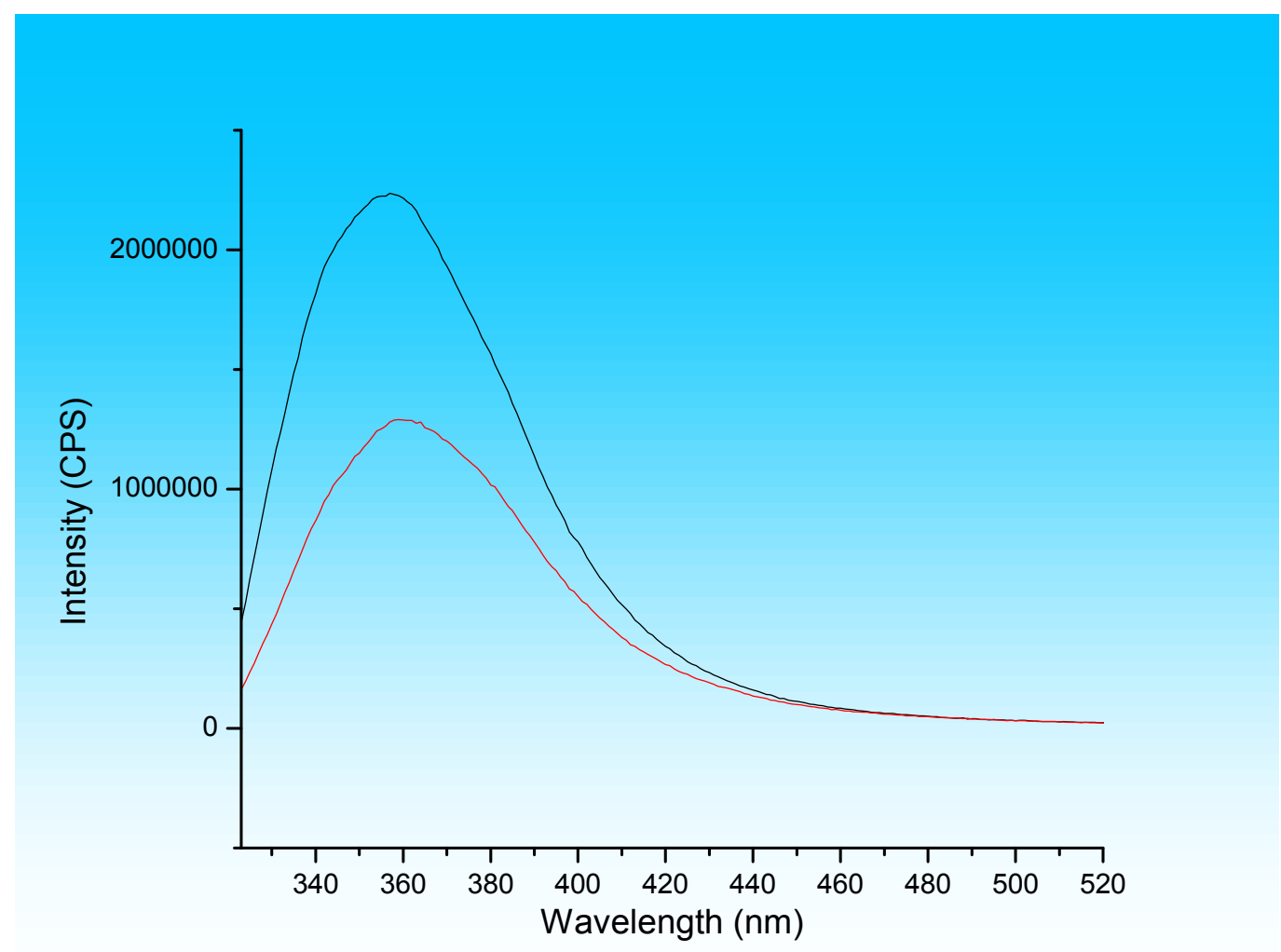

Figure S10. Fluorescence spectra of guest $1 \mathrm{a}\left(1 \times 10^{-5} \mathrm{M}\right.$, black $)$ and that of $1 \mathrm{a}$ in presence of 2 equivalents of $\beta-C D$ (red). Excitation wavelength: $300 \mathrm{~nm}$. 


\section{Reference}

1. Yue, D.; Yao, T.; Larock, R. C. Synthesis of 2,3-disubstituted benzo[b]furans by the palladium-catalyzed coupling of o-iodoanisoles and terminal alkynes, followed by electrophilic cyclization. J. Org. Chem. 2005, 70, 10292-10296.

2. Rubin, M.; Trofimov, A.; Gevorgyan, V. Can Polarization of Triple Bond in Tolanes Be Deduced from $13 \mathrm{C}$ NMR Shifts? Re-evaluation of Factors Affecting Regiochemistry of the Palladium-Catalyzed Hydrostannation of Alkynes, J. Am. Chem. Soc. 2005, 127, 10243-10249. 